\title{
Diagnosis and Efficacy Improvement of Staff Training in Medium- and Small-Sized Private Enterprises
}

\author{
Lujian Zheng, Jianmin Wang* \\ School of government, Beijing Normal University, Beijing, China \\ Email: zhenglujian@bnu.edu.cn, *wangjianmin@bnu.edu.cn
}

How to cite this paper: Zheng, L.J. and Wang, J.M. (2018) Diagnosis and Efficacy Improvement of Staff Training in Mediumand Small-Sized Private Enterprises. American Journal of Industrial and Business Management, 8, 710-720.

https://doi.org/10.4236/ajibm.2018.83048

Received: March 5, 2018

Accepted: March 25, 2018

Published: March 28, 2018

Copyright (c) 2018 by authors and Scientific Research Publishing Inc. This work is licensed under the Creative Commons Attribution International License (CC BY 4.0).

http://creativecommons.org/licenses/by/4.0/

\begin{abstract}
Socioeconomic development has intensified inter-enterprise competition and made human resource exploitation extremely important for all enterprises. As a major part of the market economy, private enterprises play an increasingly important role. Staff training, a key step of human resource development, is critical for improving individual performances and overall corporate performance \& yield. However, the staff training of medium- and small-sized private enterprises is faced by many problems that restrict the training efficacy. To further diagnose the training-related problems faced by medium- and small-sized private enterprises, here the author analyzed the current situations of staff training in $\mathrm{M}$ and identified the problems. Together with relevant knowledge and theories, the author analyzed underlying causes and proposed appropriate suggestions, aiming to provide some references and guidance for improving the training system of $\mathrm{M}$.
\end{abstract}

\section{Keywords}

Organizational Diagnosis, Human Resource Development, Education Training, Efficacy Improvement

\section{Introduction}

Socioeconomic development and technical progress have opened a knowledge economy era and intensified inter-enterprise competition [1]. In addition to resources, scales and quantity, the speed of economic development also depends on the accumulation \& utilization of knowledge, information and skills. The staff, as the carrier of knowledge, becomes the largest capital of competitive advantage and the major constraint on economic development for all enterprises. 
Any enterprise expecting to survive and develop well in the intense social competition must possess a powerful human resource team [2]. Thus, cultivating an adaptive and competitive talent team is urgent for a sustainable enterprise. Moreover, as one of the core business sections of human resource management, staff training is very valuable and critical in improving the personal quality and skills of employees and promoting the yields \& performances of the staff and the whole enterprise. Staff training is constructive to talent reservation and management costing reduction, and to enhancing staff overall quality and harmonizing intra-enterprise atmosphere. Reversely, the lack of complete training system and the presence of problems would limit further corporate development [3]. Currently, the training systems of some enterprises are faced with many problems, such as the ignorance of leaders over training, lack of financial support, lack of auxiliary training systems, lack of professional trainer team, and overformalization of training efficacy assessment. Thus, it is urgent to accelerate the improvement of enterprise training systems, establish appropriate training plans and thereby promote the overall quality and working ability of the staff.

As a major part of the market economy, private enterprises in China play an increasingly important role following the considerable support and cultivation by the central government. However, the training activities of some mediumand small-sized private enterprises are faced by many problems, which restrict the training efficacy and decelerate the staff ability and quality training [4]. Thus, targeting at $\mathrm{M}$ as a case and together with relevant theories and knowledge, the author probed into the problems of staff training in $\mathrm{M}$ and put forward appropriate suggestions. The findings would offer some references and guidance for the improvement of training system, promotion of overall core competitiveness, and acceleration of corporate development in M [5].

\section{Current Situations and Problems in Staff Training of $M$}

\subsection{Profile and Current Training Situations}

$\mathrm{M}$ is a medium-size private tire manufacture and marketing enterprise in Beijing and possesses over 1000 employees. It has set up an administration \& logistics department, a human resource department, a finance department, a law department, a marketing department, a manufacture department, and a technology department.

The human resource department has two professional employees responsible for staff training and management [6]. The enterprise training levels are divided into first level (enterprise level) and second level (department level, group level). Each department has a part-time training manager in charge of organizing department-level training and supervising the implementation of training. The employees undergoing training (trainees) are divided by the level of position into business management staff, professional technical staff, skill staff, and administrational staff (The training contents mainly include national laws and regulations, corporate management system and program documents, positional theo- 
ries and knowledge, practical operational skills, technical standards, typical quality cases, safety education, and admission training [7]. For professional technique and skill training, new employees would be tutored by old employees and given one month of apprentice. New employees would be guided and instructed by old employees with more than 3 years of service in a one-to-one way and taught with the operational skills and experiences at the corresponding position [8]. As for corporate management system, regulation and safety training, relevant leaders are organized to give 2- to 3-h lectures once every half year, and then all employees are provided with relevant materials for learning and review later. The trainees are checked through written examination [9]. As for technical standard training, the company invites a foreign expert to give a 3-day training every two months, 2 hours each day, and plans 2 hours of training off work for the employees. The company's training system is shown in Figure 1.

\subsection{Problems in Staff Training of $M$}

Two years ago, $M$ converted the former personnel department into the human resource department and arranged two professional employees in charge of training. Generally, $\mathrm{M}$ has made some progress in exploration and practice of training, and has gradually enriched the training contents [10]. However, according to the author's observation and reviews with some employees, there are still some problems that should be solved.

\subsubsection{Overformalization of Demand Investigation}

Based on the author's work experiences and reviews with some employees, $M$ has no appropriate training demand investigation (Attachment 1), which modestly restrains the overall training efficacy [11]. At present, $M$ issues one questionnaire at the year end, aiming to understand the training demands of employees. The department-level employees in charge would collect the questionnaire and hand over to the human resource department, which thereby would formulate the training plans for the coming year. The first problem is that the

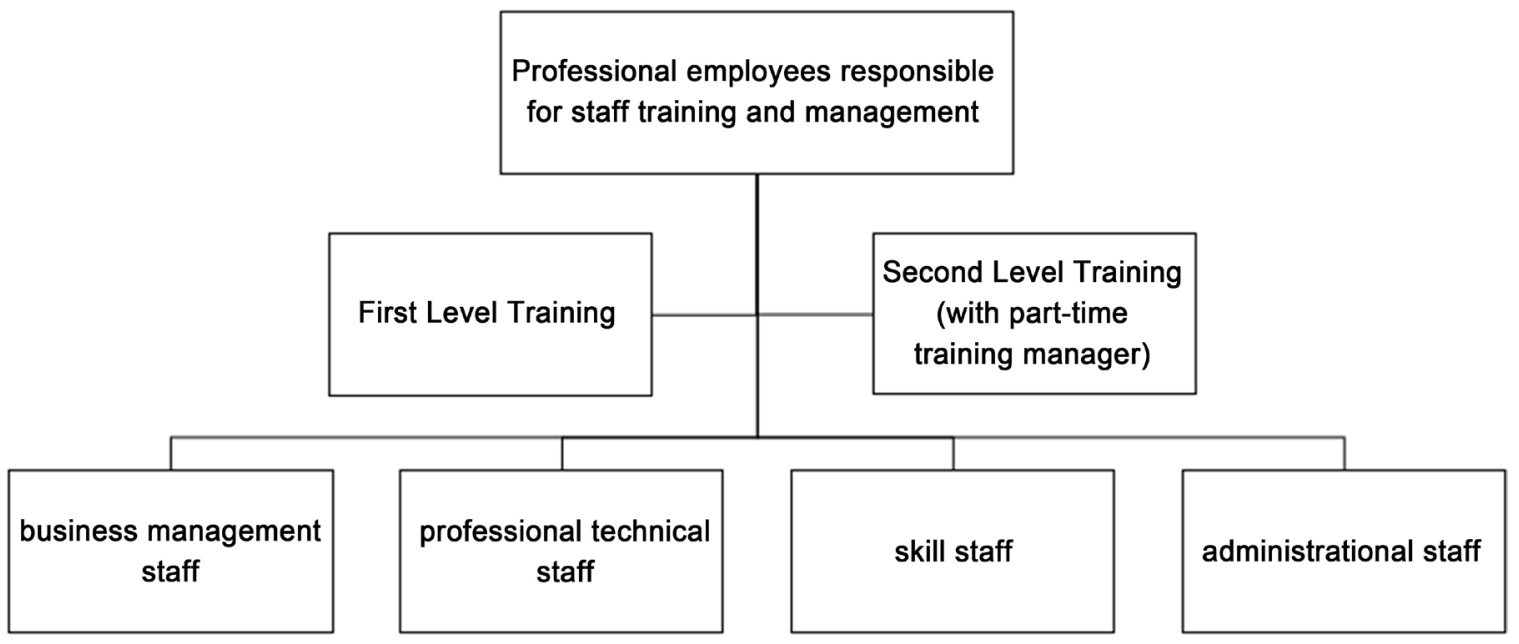

Figure 1. The company's training system. 
questions on the questionnaire are too simple and many of them are open topics, which make some first-line less-educated employees unable to respond [12]. Secondly, employees from some departments are slipshod in work and sometimes do not send the questionnaire to the first-line employees, who are then replaced by the group leader to fill in. As a result, the filled contents on the questionnaire are much identical. In the long run, the demand investigation planned as a basic training work becomes formalized and does not help with the training. Moreover, the training targets and contents could not be pertinently determined, which would reduce the training efficacy and thereby does not satisfy the demand for employee development and organizational strategies [13].

\subsubsection{No Pertinence of Training Contents}

Some of the training contents are vacuous and practically unfeasible. With professional skill training as example, the company invites a foreign expert to give lectures. Though this expert could communicate with Chinese employees in Chinese, the contents of training skills are overly theorized and derailed from real manufacture and equipment operations [14]. Moreover, the contents could not be well applied into manufacture or processing. Thus, the employees psychologically repel such training, and some even complain that the company spends so much on a foreign expert, but the contents are flashy and non-pertinent. They think the company should better invite an experienced employee to share and teach them. Therefore, the employees are not very enthusiastic or passionate about such training, which makes the training efficacy unideal. Moreover, the company has no occupational quality training as described in the positional descriptions, and the training contents are not pertinent, diverse or interesting. The training contents of interest include interpersonal communication, team work, problem analyzing and solving ability, and sunshine state of mind.

\subsubsection{Lack of Professional Trainers}

$\mathrm{M}$ has no professional trainers yet. As mentioned above, all employees are periodically trained with operational skills by a foreign expert. The rules, regulations, quality standards and safety education are alternately trained by the department directors temporarily. The operational skills for new employees are trained in an apprentice way, or namely the new employees are guided by old employees. The company assigns some old employees with good performance and rich working experience to teach new employees relevant skills and experiences. Though the trainers selected by the human resource department have rich working experiences in the company, their educating abilities differ largely, owing to the lack of professional skill training [15]. Even worse, some trainers are not fluent in verbal expositions, or are not passionate or friendly to the new employees. Moreover, many trainers are not well prepared, which reduces the training efficacy.

\subsubsection{Incomplete Training Assessment and Feedback Mechanism}

$\mathrm{M}$ has no complete training assessment and feedback mechanism. Training efficacy 
assessment is the final step of corporate training and is very critical for training works. Training assessment helps to well understand the realization of goals, the benefits and training efficacy of employees, and the problems and limitations of the training. However, $\mathrm{M}$ does not adopt any prompt or reasonable measures after one training to assess the training efficacy and feedback, which leads to the loss of training assessment mechanism [16]. Except for rule and regulation training, other training activities are not designed with examination to check or feed back to the employees' training efficacy; neither are other periodical systemic examinations set up. Consequently, the training contents are not related to the employees' working performance, or to their occupational career development, which severely reduce their passion to join in training. Moreover, the training contents and targets are not comprehended promptly in effective ways, which is unfavorable for the adjustment or improvement of subsequent training lessons.

\subsubsection{Lack of Training Incentive Mechanism}

The training incentive mechanism is an efficient way to improve the training quality, as it can efficiently stimulate the employees' passion to join in training, and encourages the trainer and trainees, improving the employees' professional knowledge and skills and better matching the employees with the positions. In reality, however, $M$ has not established any auxiliary incentive system, as it does not reward the outstanding trainees or award the excellent trainers who have made significant contributions. In particular, the trainers of the apprentice systems are not awarded and some become less passionate or even impatient to the new employees. Moreover, $M$ does not connect the employees' training efficacy with their promotion or wages/bonus, which modestly reduces the enthusiasm or initiatives of employees and trainers. As a result, some training works are overformulated, and no achievements as expected have been made.

\subsection{Analysis of Causes}

Together with relevant knowledge and personal working experiences, the author thinks the above training problems faced by $M$ are attributed to several causes. Firstly, the leaders of $M$ are unclear about the importance of staff training [17]. Some leaders consider staff training as a type of costing and think such training consumes a part of corporate funds and delays the work time, thereby reducing the corporate performance. However, they do not know staff training is a long-term investment for any enterprise. Owing to the ignorance about the importance of staff training, staff training is not largely supported by the leaders, which largely reduces the training efficacy. Secondly, auxiliary fund support is insufficient. Due to lack of attention and support from the leaders, fund transfer is insufficient, which could reduce the training quality. Due to the fund shortage, the human resource department is unable to invite professional trainers, successfully organize works, or establish material incentives. Thirdly, there is no systemic training system or mechanism. Only the establishment of a scientific and appropriate 
training system/mechanism could guarantee the successful conduction of training works and help to achieve the training effects as expected. At present, $M$ has no sufficient training demand investigation, training evaluation mechanism or incentive mechanism [18]. Thus, only the establishment of relevant training mechanisms would make the training system perfect.

\section{Measures and Suggestions}

$\mathrm{M}$ is faced with some problems in staff training. Together with theoretical knowledge and personal working experiences, the author thinks $M$ could improve and optimize its training system from the following aspects, which will provide $\mathrm{M}$ with some guidance in staff training.

\subsection{Pay Attention to Training Works and Increase Fund Support}

Firstly, corporate leaders concerned should change their cognition and views about staff training, and know the importance of staff training to the individual performances and overall corporate performances. They should consider staff training as a long-term investment and give more attention and support. $\mathrm{M}$ should appoint some training funds, increase fund investment, and formulate appropriate ways of fund use and budget, which provide sufficient finance for the successful employment of training works.

\subsection{Appropriate Training Demand Investigation}

The workers at the human resource department should first, through on-site visit, understand the employees' real thoughts, and then according to preliminary interviews, draft a formal questionnaire and send it to all departments. The employees who propose good training demands should be awarded, which would arouse their enthusiasm. Understanding the employees' real demands would make the staff training plans more practical.

\subsection{Improving Professional Levels of Trainers}

$\mathrm{M}$ should strengthen the construction of a corporate trainer team by building up a trainer team with rich experiences and high professional levels. Aperiodical training would improve the trainers with standardized teaching contents and higher teaching skills. Therefore, the teaching contents would be closer to the real work demands and be more pertinent and operable. Other measures should be taken to make the training contents interesting, arouse the employees' passion and interest, and improve the overall training efficacy.

\subsection{Appropriate Training Efficacy Assessment}

Training assessment is the final stage of staff training. The realization of goals and the efficacy of training plans can be evaluated by establishing efficacy assessment indices and an assessment system. Then the evaluation results are fed back to relevant departments and used as one of the bases for subsequent train- 
ing plans and training demand investigation. $M$ can adopt self-assessment and tests. In terms of self-assessment, a questionnaire can be designed in advance, including training time, training environment, training contents, grasp of relevant knowledge or skills, and levels of trainers. Then after the training, the employees are asked to fill in the questionnaire in a programed or open way. In terms of tests, according to different positions, knowledge-based training can be evaluated through written examination, while skill-based training can be evaluated via on-site (simulated) tests.

\subsection{Establishment of Good Training Incentive Mechanism}

Only a good incentive mechanism can well stimulate the trainees and trainers to work actively and join passionately in the training activities, thereby improving the training efficacy to the largest extent. Material awards can be used, such as incentive rewards and bonus. The trainers or trainees with higher training performances can be given incentive awards or be encouraged by meeting their demands, which would enhance the training performance and effectiveness. Moreover, an honor incentive mechanism can be used. Specifically, the employees and trainers with better training performances are awarded with honor certificate or title, praised in front of the whole company, and given opportunity of preferential promotion, which would inspire the employees to join in staff training. $M$ should also enlarge material awards to excellent trainers and trainees, which ensure the overall effectiveness and successful progress of staff training.

\section{Conclusions}

Staff training is a key step of human resource management and development. Starting from its strategies and targets, an enterprise should establish a complete training system/mechanism, select appropriate methods for analysis of training demands, and carry out scientific and effective training activities. It should also targetedly select training contents and pay attention to the importance of training evaluation and incentives. Only these measures can effectively arouse the employees' enthusiasm and passion of participation, largely improve the training efficacy, fully utilize the potentials of employees, promoting their knowledge and skill levels, and well match the employees with the positions, thereby enhancing the organizational performance and competitive advantage. During daily manufacture and operation, enterprises should pay attention to the investment of human capitals, the values of human resources, and the important roles of staff training in manufacture and corporate development.

This study has important guiding significance for the development of corporate training in the future. It is recommended that enterprises clarify the training needs, improve the level of trainers, conduct a reasonable assessment, and optimize the incentive mechanism so as to achieve a better training effect.

As this study takes $M$ company as a case and the sample is relatively single, in 
the future research, case studies can be carried out for other types of companies.

\section{Fund}

This paper is supported by "the Fundamental Research Funds for the Central Universities".

\section{References}

[1] Liu, J.R. (2005) Theoretical and Empirical Study about Effects of Personal and Organizational Factors on Corporate Training Performance. East China Normal University, Shanghai. (In Chinese)

[2] Wang, Y.J. and You, Y.X. (2012) Problems and Measures about Enterprise Staff Training based on Training Effectiveness. Enterprise Economy, 5, 91-93. (In Chinese)

[3] He, Y.X. (2003) Enterprise Human Resource Training-Theories, Principles, Problems and Ways of Training. Wuhan University of Science and Technology, Wuhan. (In Chinese)

[4] Li, S., et al. (2012) Problems and Countermeasures of Staff Training in Enterprises. Journal of Yunnan Agricultural University (Social Science), 6, 20-24. (In Chinese)

[5] Li, Q. (2007) Effectiveness of Enterprise Staff Training. Southwestern University of Finance and Economics, Chengdu. (In Chinese)

[6] Feng, J. (2007) Enterprise Staff Training and Development. Beijing Jiaotong University, Beijing. (In Chinese)

[7] Wang, P.Y. (2013) Problems and Countermeasures of Training in Small- and Medium-Sized Enterprises. Enterprise Economy, 5, 76-79. (In Chinese)

[8] Zhou, J.Y. (2014) Problems and Countermeasures of Staff Training in Small- and Medium-Sized Enterprises. Guangxi Normal University, Guilin. (In Chinese)

[9] Meng, T. (2007) Enterprise Training Patterns. Qingdao University, Qingdao. (In Chinese)

[10] Huang, J. (2005) Analysis and Modeling of Enterprise Training Demand in China. Chongqing University, Chongqing. (In Chinese)

[11] Wang, R.Y., et al. (2011) Human Resource Management. Science Press, Beijing. (In Chinese)

[12] Guo, W.W. (2002) Enterprise Training Based on Organizational Learning. Zhejiang University, Hangzhou. (In Chinese)

[13] Li, B. (2009) Learning Organization Theory of Peter Senge. Enterprise Reform and Management, 7, 59-61. (In Chinese)

[14] Yang, H.C., et al. (2004) Review on Studies of Training Management Conditions in Chinese Enterprises. Scientific Management Research, 22, 103-107. (In Chinese)

[15] Feng, Y.X. and Wu, A.Y. (2002) Influence Factors on Enterprise Training. Human Resource Development of China, 6, 21-24. (In Chinese)

[16] Li, D. and Zhao, H. (2006) Brief Discussion of Evaluation of Enterprise Training Effect. Science \& Technology Progress and Policy, 23, 124-125. (In Chinese)

[17] Zhao, B.T. and Xie, X.B. (2008) Evaluation of Enterprise Training Effect. Science and Technology Management Research, 28, 395-397. (In Chinese)

[18] Huang, J.Y. and Shen, F. (2009) Countermeasures and Suggestions on Improving Enterprise Training System and Training Quality. Vocational \& Technical Education Forum, 19, 36-39. (In Chinese) 


\section{Attachment 1}

\section{Staff Training Needs Survey}

Dear colleagues,

In order to do a good job of training in 2012, employees' work skills and training satisfaction were improved and the company's development strategy was realized so that the training work truly reflected the needs of employees and the company. Offices for the company staff to carry out 2011 annual survey of training needs through communication and understanding all visions of the training, the actual needs, suggestions and expectations.

Findings will be developed for the company 2012 annual training program provides an important reference and basis for, the questionnaire also provides an opportunity for you to express your own constructive comments, your opinion will help to achieve your training needs, while also To promote the improvement and improvement of the company's training system, and more importantly, your active participation will help the smooth implementation of company training and lay a solid cultural foundation for the company's development.

Thank you very much for taking the time to complete this questionnaire and thank you for your support and assistance in our training.

\begin{tabular}{|c|c|c|c|}
\hline \multicolumn{4}{|c|}{ First, basic information } \\
\hline \multicolumn{2}{|c|}{ Names } & \multicolumn{2}{|l|}{ department } \\
\hline post & & \multicolumn{2}{|l|}{ Entry Time } \\
\hline \multicolumn{4}{|c|}{ Second, training status survey (please tick “ $\sqrt{ }$ ” in your accepted answer “ $\square$ ”) } \\
\hline 1. & Do you think the current company's emphasis on training? & $\begin{array}{l}\square \text { Great emphasi } \\
\square \text { General }\end{array}$ & $\begin{array}{l}\square \text { More attention } \\
\square \text { To be strengthened }\end{array}$ \\
\hline 2. & Section if your are training program as planned training work? & \multicolumn{2}{|c|}{$\begin{array}{l}\square \text { Planned and planned } \\
\square \text { Planned but not planned } \\
\square \text { No plan but training } \\
\square \text { No plan, no training }\end{array}$} \\
\hline 3. & $\begin{array}{l}\text { You have participated in several training courses this year (including } \\
\text { company-level and department-level training) }\end{array}$ & \multicolumn{2}{|c|}{$\begin{array}{l}\square 1-2 \text { times } \square 3-4 \text { times } \\
\square 5-6 \text { times } \square 7-8 \text { times } \square 9-10 \text { times }\end{array}$} \\
\hline 4. & Regarding the level of teaching teachers at all levels of training this year, you think: & $\begin{array}{l}\square \text { very high } \\
\square \text { General }\end{array}$ & $\square$ relatively high \\
\hline 5. & For the frequency of training at all levels this year, you think: & $\begin{array}{l}\square \text { very high } \\
\square \text { General }\end{array}$ & $\begin{array}{l}\square \text { relatively high } \\
\square \text { Low } \quad \square \text { Low }\end{array}$ \\
\hline 6. & For the timing of training at all levels this year, you think: & $\begin{array}{l}\square \text { very reasonable } \\
\square \text { General } \\
\square \text { Unreasonable }\end{array}$ & $\begin{array}{l}\mathrm{e} \square \text { more reasonable } \\
\square \text { Not reasonable }\end{array}$ \\
\hline 7. & How do you personally feel through the company's training at all levels? & $\begin{array}{l}\square \text { very large } \\
\square \text { General }\end{array}$ & $\begin{array}{l}\square \text { relatively large } \\
\square \text { Not great } \quad \square \text { No gain }\end{array}$ \\
\hline 8. & How do you feel about the overall company training? & $\begin{array}{l}\square \text { very satisfied } \\
\square \text { General } \\
\square \text { Not satisfied }\end{array}$ & $\begin{array}{l}\square \text { relatively satisfied } \\
\square \text { Not very satisfied }\end{array}$ \\
\hline 9. & $\begin{array}{l}\text { What factors do you think are currently affecting the effectiveness of training? } \\
\text { (Can be multiple choices, limited to three items) }\end{array}$ & $\begin{array}{l}\square \text { The timing is } n \\
\square \text { Course content } \\
\square \text { The trainer's te } \\
\square \text { Staff training a } \\
\square \text { Form too mon } \\
\square \text { The leadership } \\
\square \text { Others }\end{array}$ & $\begin{array}{l}\text { tot suitable } \\
\text { eaching level is limited } \\
\text { wareness has not kept up } \\
\text { otonous } \\
\text { does not pay enough attention }\end{array}$ \\
\hline
\end{tabular}




\section{Continued}

10. What do you think is the current need for improvement in company training? (Multiple choices, limited to 3 items):

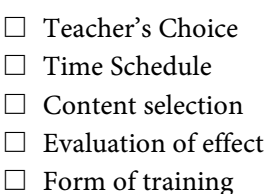

$\square$ Form of training

3. Survey of Training Needs (please tick " $\sqrt{ }$ ” in the answer “ $\square$ ”). If you choose "Others", please briefly describe in the space.)

1 You think that the training focus of the company should be (multiple choices, limited to 3 items):

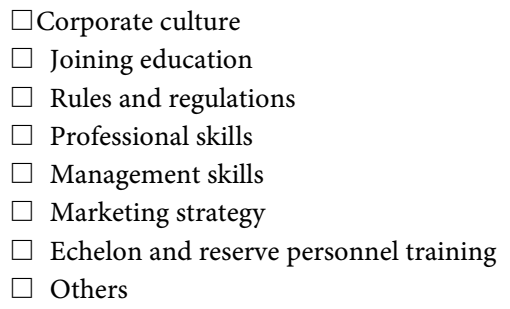

2 The frequency with which you want to participate in various company training is:

\begin{tabular}{|c|c|c|c|}
\hline \multicolumn{4}{|c|}{$\square$ once a week } \\
\hline$\square$ & \multicolumn{3}{|l|}{ twice a month } \\
\hline & \multicolumn{3}{|l|}{ once a month } \\
\hline$\square$ & \multicolumn{3}{|l|}{ once every two months } \\
\hline$\square$ & \multicolumn{3}{|l|}{ once every quarter } \\
\hline \multicolumn{4}{|c|}{$\square$ Inside the company } \\
\hline \multicolumn{4}{|c|}{ Inside the department } \\
\hline \multicolumn{4}{|c|}{$\square$ Inside the section } \\
\hline \multicolumn{4}{|c|}{$\square$ Others } \\
\hline$\square$ & lectures in class & $\square$ & case studies \\
\hline \multicolumn{4}{|c|}{$\square$ simulation operations } \\
\hline \multicolumn{4}{|c|}{$\square$ Audiovisual Multimedia } \\
\hline$\square$ & Game Contest & $\square$ & Seminar \\
\hline \multicolumn{4}{|c|}{$\square$ Others } \\
\hline$\square$ & rich knowledge & $\square$ & eloquent \\
\hline$\square$ & vivid and humorous & $\square$ & rational \\
\hline$\square$ & Working hours & $\square$ & Night time \\
\hline$\square$ & Weekend time & $\square$ & Others \\
\hline$\square$ & \multicolumn{3}{|c|}{ Half an hour to one hour } \\
\hline$\square$ & \multicolumn{3}{|l|}{ One hour to two hours } \\
\hline & more than two hours & & \\
\hline & no matter & & \\
\hline
\end{tabular}

8 You personally feel that there is the following confusion in your work? (please fill out the facts, you can choose more!) $\square$ High work pressure, sometimes depressed or depressed due to work reasons \{Consider the introduction of Stress and Emotion Management\}.

$\square$ Work tasks have a lot of personal feelings, and they always feel busy and busy. \{Consider introducing Time Management\}.

$\square$ When and colleagues to do together, feeling a lack of communication smooth \{consider the introduction of "teamwork and communication management"\}.

$\square$ When work colleagues and made into a disagreement, sometimes I do not know what to do, or not feeling well after the treatment effect \{consider the introduction of "interpersonal and conflict management"\}.

$\square$ Personally feel that the work has been hard, but the goal is still not complete, or the leader sometimes feels dissatisfied \{Consider the introduction of "Management and execution of objectives"\}.

$\square$ In daily activities, some of the individuals' behaviors do not know whether they are appropriate or not, and whether they meet the requirements of etiquette \{consider the introduction of "business etiquette"\}.

$\square$ Other (please specify)

1 ,

2 ,

3 , 
9 In terms of professional knowledge and theory, combined with your personal career development plan, please list three aspects that you personally feel most need to improve:

1 ,

2 ,

3 ,

IV. Training Suggestions (If you have any good suggestions for the training of the company, please put it in the table below, thank you!!!) 